\title{
A NEW TRICHODECTES FROM BAJA CALIFORNIA.
}

\author{
By V. L. Kellogg and S. Nakayama, \\ Stanford University, Cal.
}

Among some old specimens of Mallophaga in the Stanford University collection we have found a male and a female of an interesting new species of Trichodectes, which is described herewith. The specimens were collected by the well-known ornithologist, R. C. McGregor, in a bird-collecting expedition to the islands off Baja California (San Martin, Cerros, Todos Santos, San Geronimo, Guadaloupe, and others). No parasites of mammals were, as far as the records show, obtained, and the specimens referred to in this paper were credited to bird hosts, the male to a Corvus semicinctus from Cerros Island and the female to Homatopus frazari from San Martin Island. There is undoubtedly error in these attributions, either in the record-keeping or by abnormal straggling in game bag or on skinning table from some mammal to these birds. The host is, therefore, unknown. The specimens are typical Trichodectes (mammal-infesting parasites), and certainly of the same species.

The new species suggests, in general shape of head, length and character of antennæ, the semi-dentate lateral margin of abdomen, and terminal segments of the male, the wide-spread and familiar Trichodectes limbatus of the goat; but the specific differences are marked. Especially is the new species distinguished by the shape of the abdomen, and great length of the tarsal claws. The abdomen of the male, in the new species, is as broad as long, almost roughly circular in outline, indeed, while in limbatus, it is elongate ovate. Also the posterior margin of the second abdominal segment bends conspicuously forward at its middle, revealing thus a broad but deep rounding posterior emargination in this segment. Thus the abdominal characters alone conspicuously distinguish this new species from any other known Trichodectes.

Trichodectes painei sp. nov. (fig. 1, A-D).

Male: Body, length $1.21 \mathrm{~mm}$;; width (across third abdominal segment), .60 mm.; general color, pale yellowish brown with darker bands and markings on head and thorax, and pronounced, although narrow, dark lateral margins of abdomen, 


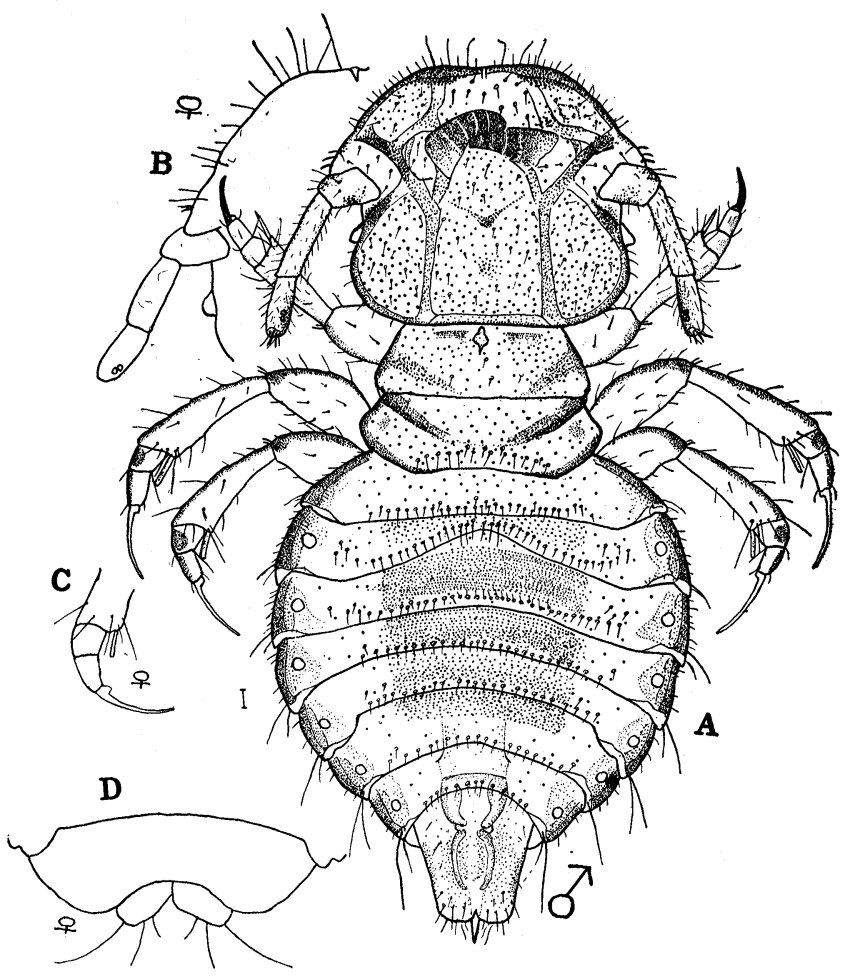

Fig. 1. Trichodectes painei sp. nov.

and distinct broad transverse bands, not reaching lateral margins, on segments 3 to 6 , inclusive, of the abdomen.

Head, length $.37 \mathrm{~mm}$; width $.46 \mathrm{~mm}$; thus being wider than long; general shape quadrangular with rounding angles; clypeal front broad and straight with a slight gradual median concavity and at the middle of the concavity a very narrow, straight incision bisecting the anterior marginal marking; trabeculæ inconspicuous; ocular fossæ slight, with eyes unusually projecting and conspicuous; posterior margin straight. Antennæ very long, when projecting backwards extending slightly beyond posterior margin, second segment almost twice as long as third, two small sense pits on third segment. A pair of straight, nearly parallel occipital bands running forward to meet diagonal antennal bands, each occipital band also sending an inner branch to the base of the mandibles.

Prothorax slightly narrower than the metathorax with both segments of about the same length; lateral margins of prothorax slightly diverging so that the segment is widest between its posterior lateral angles. Metathorax widest in the middle with a projecting obtuse angle at the middle of each lateral margin; from these 
obtuse angles the posterior margin runs back and inward in a flatly curving line for about one third of the width of the segment, the middle third of the posterior being straight, with a shallow concavity. A series of fine but distinct short hairs in a series roughly parallel with the slightly concave but nearly straight third of the posterior margin of the metathorax. Straight diagonal bands of darker color showing through each thoracic segment from the underside. Legs conspicuously long, largely because of the unusual length of tibiæ, tarsi and claws; tibiæ growing wider toward tip and bearing a short, strong, blunt, spineless projection at the inner angle of the tip; tarsi of middle and hind legs with claws of unusual length, each claw being longer than both tarsal segments together and more than half as long as the tibia; claws of the forelegs but a little more than half as long as those of middle and hind legs, but more strongly chitinized.

Abdomen, length $.64 \mathrm{~mm}$., width $.60 \mathrm{~mm}$.; almost roughly circular in outline, although really broader in front than behind, and with the projecting, tapering last segment and genitalia destroying the circular outline. Second segment with deeply but broadly emarginate posterior border. Lateral margins almost dentate because of the projecting postero-lateral angles of each segment. Each segment bearing a series of many fine short hairs along the median two thirds of the posterior margin; longer but inconspicuous hairs projecting from the postero-lateral angles of the segments. Strongly colored, but narrow, lateral borders on all segments; and conspicuous dark median transverse blotches covering most of the dorsum (for the middle half of its width) on segments three to six inclusive; last segment of abdomen narrow and projecting backward with the genitalia showing distinctly.

Female: Body, length $1.57 \mathrm{~mm}$; head $.46 \mathrm{~mm}$., width $.56 \mathrm{~mm}$; length of abdomen .88 , width .69 $\mathrm{mm}$., the abdomen thus being considerably longer than broad, and hence not of the nearly circular shape of that of the male. The antennæ are not as long and slender as those of the male, the second segment being only slightly longer than the third. The ground color of the body and markings both paler than in the male, but the markings and blotches about the same in arrangement and character.

The species name painei is given for Mr. J. H. Paine, an active American student of the Mallophaga. 

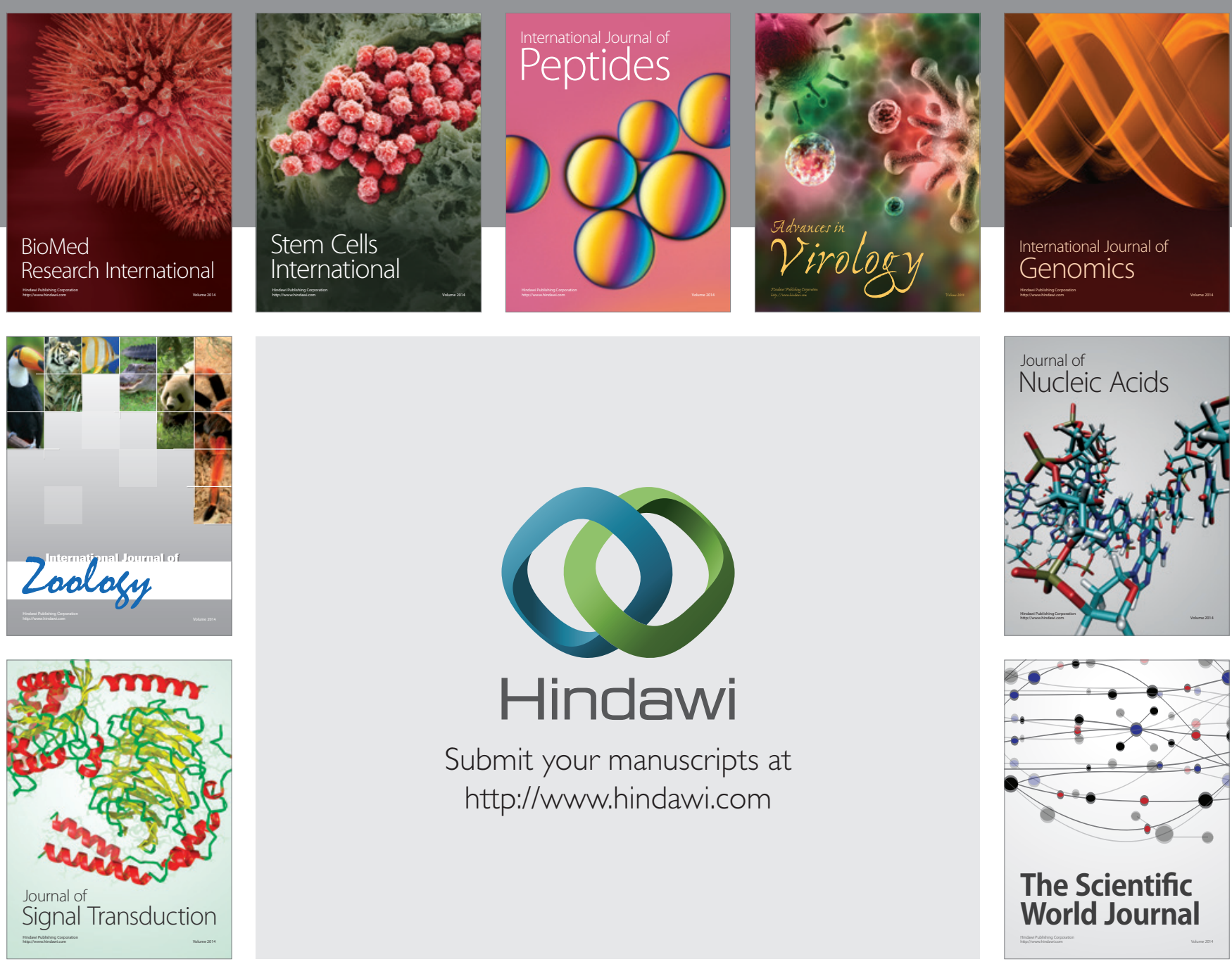

Submit your manuscripts at

http://www.hindawi.com
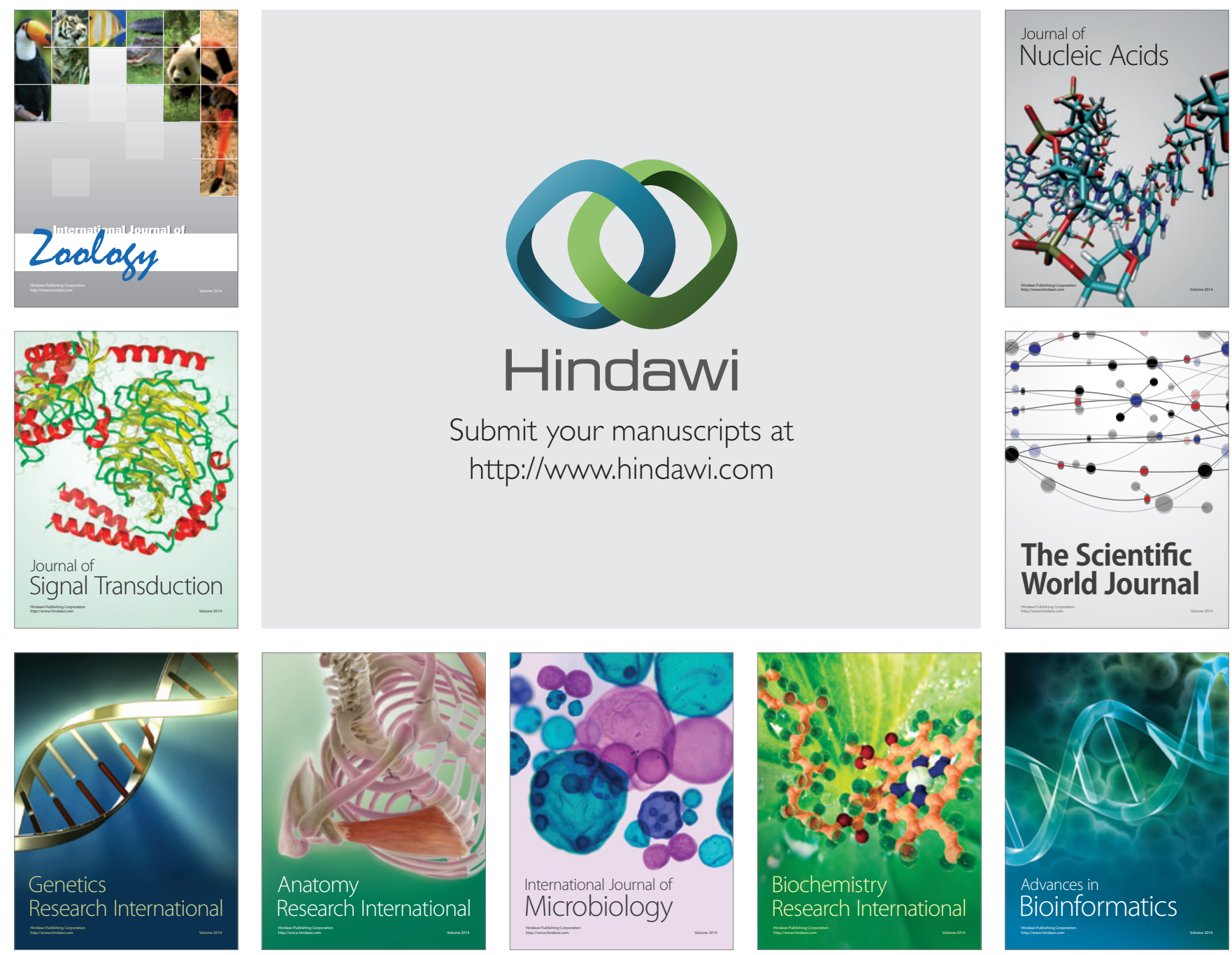

The Scientific World Journal
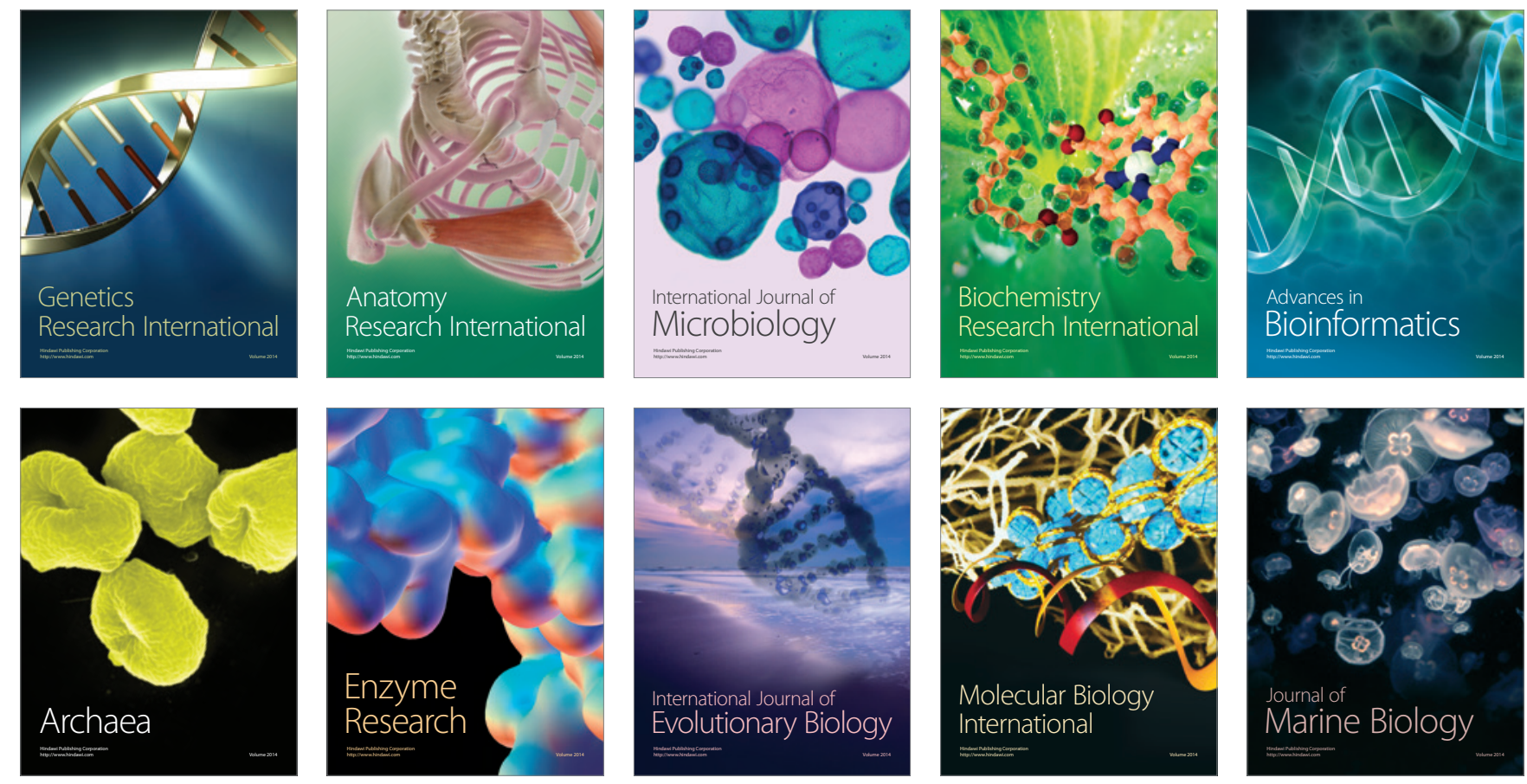